\title{
Representações sociais sobre os esportes de aventura na educação física
}

\author{
Social representations about adventure sports in physical \\ education
}

Felipe Triani ${ }^{1}$

Silvio de Cassio Costa Telles ${ }^{2}$

\begin{abstract}
Resumo
Os esportes de aventura vêm ganhando cada vez mais espaço na sociedade atual, não sendo diferente em ambientes educacionais. Na escola, as praticais corporais de aventura têm sido, aos poucos, inseridas como tendência, principalmente nas aulas de educação física, ação que se encontra referenciada na Base Nacional Comum Curricular. Nesse sentido, o manuscrito buscou identificar e discutir as representações sociais que alunos do $4^{\circ}$ ano do Ensino Fundamental de um colégio particular de Duque de Caxias/RJ possuem sobre os esportes de aventura. Para atingir o objetivo do estudo, além de utilizar a Teoria das Representações Sociais como base de sustentação teórica, foi adotada uma pesquisa de campo com abordagem qualitativa, na qual 43 estudantes participaram por meio do teste de associação livre de palavras. Os resultados apontaram "esportes com bola", "sentimento", "saltos radicais", "escalada", "exploração" e "corrida" como grupos semânticos associados aos esportes de aventura que permeiam o núcleo central do grupo investigado. Portanto, concluiu-se que há necessidade de práticas pedagógicas de intervenção já no $4^{\circ}$ ano para possiveis transformações sobre as representações sociais engendradas acerca dos esportes de aventura.
\end{abstract}

Palavras-chave: Esporte. Escola. Educação física escolar. Prática pedagógica.

\begin{abstract}
Adventure sports are gaining more and more space in today's society, not being different in educational settings. In the school, corporal practices of adventure have been inserted, as a tendency, mainly in the classes of physical education, action that is referenced in the National Base Curricular Common. In this sense, the manuscript sought to identify and discuss the social representations that students of the 4th year of elementary school in a

\footnotetext{
${ }^{1}$ Doutorando em Ciências do Exercício e do Esporte na Universidade do Estado do Rio de Janeiro - UERJ. Email: felipetriani@gmail.com

2 Doutor em Educação Física - UGF. E-mail: silviotelles@terra.com.br.
}

Interfaces da Educ., Paranaíba, v.10, n.30, p. 246 -267, 2019

ISSN 2177-7691 
private school in Duque de Caxias/RJ have on adventure sports. To achieve the objective of the study, in addition to using the Theory of Social Representations as a basis for theoretical support, a field research with a qualitative approach was adopted, in which 43 students participated through the free word association test. The results pointed to "sports with ball", "feeling", "radical jumps", "climbing", "exploration" and "race" as semantic groups associated with adventure sports that permeate the core of the group investigated. Therefore, it was concluded that there is a need for pedagogical practices of intervention already in the 4th year for possible transformations on the social representations engendered about adventure sports.

Keywords: Sport. School. School physical education. Pedagogical practice.

\section{Introdução}

Esportes californianos, esportes radicais de ação, esportes radicais de aventura (PEREIRA, ARMBRUST, 2008), esportes radicais, turismo de aventura, esporte de aventura, turismo esportivo, esportes na natureza, atividade física na natureza, atividade de aventura (MARINHO, 2013), práticas corporais de aventura (BRASIL, 2018) e outras terminologias são empregadas para se referir às práticas corporais estabelecidas na relação do homem com a natureza.

Dentre um universo de conceitos possiveis, optou-se pelo proposto por Costa, Marinho e Passos (2007), também adotado pelo Ministério do Esporte, que compreendem o termo esporte de aventura como o conjunto de práticas esportivas que podem ser vivenciadas em ambientes educacionais, de lazer ou de rendimento, sob controle do uso de equipamentos, da formação de recursos humanos e comprometimento socioambiental, desde que exista interação com a natureza, possibilitando a emergência de emoções sob condições de incerteza em relação ao meio e com risco calculado. A prática ${ }^{3}$ pode ser realizada em ar, água, neve, gelo e terra, por meio da exploração das possibilidades da condição humana.

Em uma revisão conduzida por Tahara e Darido (2016) foram realizadas reflexões sobre as práticas corporais de aventura e sobre a educação física escolar. $\mathrm{Na}$ pesquisa, foram eleitos três pontos a serem

\footnotetext{
${ }^{3}$ Os esportes de aventura se enquadram na compreensão clássica que considera esporte como a prática institucionalizada (TUBINO; TUBINO; GARRIDO, 2007). No entanto, como algumas modalidades ainda não foram institucionalizadas, comumente adotam-se os termos "atividades de aventura" e/ou "práticas corporais de aventura".
} 
discutidos, sendo o primeiro a questão terminológica dessa prática, o segundo os objetivos e dificuldades da inserção dessa prática na escola, e o terceiro, que é ensinado nas aulas, tem as práticas corporais de aventura como conteúdo. Nesse contexto, o estudo concluiu que as práticas corporais de aventura compreendem uma série de possibilidades, sendo aquáticas, terrestres, na natureza ou em meio urbano, e ainda que há várias maneiras de adaptar o conteúdo para possibilitar essa prática na escola. Portanto, a revisão concluiu que a importância desse conteúdo está na possibilidade de oportunizar a experiência da prática corporal de aventura às crianças e jovens, enquanto uma possibilidade pedagógica emergente da área de educação física.

Outra revisão recentemente publicada (PAIXÃO, 2017) buscou identificar as possibilidades de trabalho das diferentes modalidades dos esportes de aventura para inserção como conteúdo da educação física escolar. Sob ótica das dimensões conceitual, procedimental e atitudinal dos conteúdos, foram encontradas as modalidades de orientação, trekking, canoagem e acampamento. Além desses, um conteúdo bastante referenciado é o de montanhismo (PEREIRA, 2013; TRIANI; MARTINS; ALVES, 2016).

Nesse contexto, as discussões sobre os esportes de aventura, enquanto objeto de estudo na literatura científica, têm proporcionado reflexões para sua inserção como conteúdo na educação física escolar. Não obstante, o documento mais recente que serve de orientação pedagógica para o país, a Base Nacional Curricular Comum (BRASIL, 2018), de maneira inovadora, incorpora as práticas corporais de aventura como unidade temática para a educação física. Porém, sugere que esse conteúdo seja trabalhado a partir do $6^{\circ}$ ano do ensino fundamental. Sendo assim, questiona-se: os alunos dos anos anteriores não compartilham conhecimentos sobre os esportes de aventura? A resposta para esse questionamento pode contribuir para que professores de educação física e pesquisadores interessados nessa temática ampliem as reflexões e discussões sobre quando e por que utilizar os esportes de aventura como conteúdo da educação física, considerando a carência quanto ao nível de ensino mais indicado para a tematização deste objeto de conhecimento. Ainda que a Base Nacional Comum Curricular Interfaces da Educ., Paranaíba, v.10, n.30, p. 246 - 267, 2019 
indique o $6^{\circ}$ ano, não há menção a uma justificativa epistemológica ou pedagógica.

A proposta desse estudo é justificável na medida em que busca no seio do ambiente escolar os conhecimentos compartilhados por estudantes sobre os esportes de aventura. Essa prática coaduna com Jodelet (2001) ao sugerir que a finalidade da pesquisa em Psicologia Social, por meio das representações sociais, é buscar identificar os conhecimentos elaborados e compartilhados no senso comum e discuti-los em contraponto com o conhecimento científico.

Nesse contexto, considerando como referencial a Teoria das Representações Sociais proposta por Moscovici (2012), há de se perceber que os conhecimentos são adquiridos na comunicação entre os sujeitos sociais. Dessa maneira, esses conhecimentos se manifestam em duas dimensões, a saber: consensual e reificada. A primeira faz referência aos conhecimentos do saber comum, representações sociais que não correspondem à veracidade científica atribuída pela literatura especializada; o segundo trata-se, portanto, do conhecimento científico, àquele que corresponde às verdades compartilhadas pelos especialistas.

De acordo com Jodelet (2001) a Teoria das Representações Sociais busca explicar o comportamento de determinados grupos sociais, sendo assim, assinala que as representações sociais que se têm sobre um determinado objeto representacional guiam o comportamento no e sobre o objeto. Dessa maneira, conhecer as representações sociais sobre os esportes de aventura e propor intervenções para modificá-las, pode contribuir para que não seja necessário chegar ao $6^{\circ}$ ano para praticá-los e/ou discuti-los enquanto conteúdo pedagógico, além de preencher a lacuna existente no que tange à produção científica concernente à esportes de aventura e representações sociais. Destarte, empoderado desse conhecimento é que o presente manuscrito tem como objetivo identificar e discutir as representações sociais que alunos do $4^{\circ}$ ano do Ensino Fundamental de um colégio particular de Duque de Caxias/RJ possuem sobre os esportes de aventura. 


\section{A Teoria das Representações Sociais}

O estudo se apresenta ancorado na Psicologia Social, mais especificamente na Teoria das Representações Sociais de Serge Moscovici (1978). A escolha desse referencial é justificável pelo fato da teoria possuir um contexto de aplicabilidade, como fez o próprio Serge Moscovici ao defender a tese que fundamentou a Teoria das Representações Sociais. Na ocasião, com o objetivo de investigar as representações sociais da Psicanálise, o autor da teoria realizou uma pesquisa de campo, tendo o homem comum como sujeito. Assim, o contexto de aplicabilidade empírica com o oferecimento de métodos justifica a escolha por essa teoria, considerando seu caráter intervencionista.

No que tange à gênese da Teoria das Representações Sociais, o próprio Serge Moscovici (2007) pontua que se apropriou da noção de representações a partir das "representações coletivas" de Durkheim (1987). No entanto, essa apropriação se deu de maneira crítica e constituiu um plano de imanência próprio da Teoria das Representações Sociais, algo que, para conhecer, algumas noções são necessárias, a saber: o motivo da substituição do termo "coletivo" por "social"; o universo reificado e o consensual; a função da teoria e suas formas de abordagem.

É fundamental saber inicialmente que "representações coletivas" e "representações sociais", embora sejam aparentemente semelhantes, conceitualmente são divergentes. Ao adotar o substantivo "representação" mais o adjetivo "social", Serge Moscovici atribuiu algumas qualificações à ideia de "representação social", pois, a utilização do adjetivo "social" corresponde ao fato de que as representações sobre um mesmo objeto variam de acordo com as condições de vida social do grupo em que emerge. Além disso, o autor argumenta que o sentido do adjetivo social está no fato de que ela "contribuiu exclusivamente aos processos de formação das condutas e de orientação das comunicações sociais" (MOSCOVICI, 2012, p. $71)$.

Ainda nessa perspectiva, o termo coletivo empregado por Durkheim corresponde a uma esfera que abarca um conjunto de formas intelectuais, como a ciência e a ideologia, sendo a primeira uma forma de entender a Interfaces da Educ., Paranaíba, v.10, n.30, p. 246 - 267, 2019 
verdade, e a segunda um sistema que justifica ações de um grupo. Nesse sentido, cada uma delas sofrem transformações específicas, de acordo com os mecanismos representativos. Assim, as formas intelectuais, isto é, mito, ideologia, religião e outras, não podem estar na mesma esfera. Essa tese constitui mais uma qualificação para a utilização de "representações sociais".

Outra noção necessária para conhecer a Teoria das Representações Sociais é a de universo reificado e consensual. Essa medida ocorre pelo fato de que as "representações coletivas" existiam, "mas ninguém se importava com sua estrutura ou com sua dinâmica interna" (MOSCOVICI, 2007, p. 45). Sendo assim, para compreender esse dinamismo, Serge Moscovici apresenta duas faces da sociedade, sendo a primeira o universo consensual no qual o ser humano é a medida de todas as coisas, e ele é o lugar em que o grupo de indivíduos se relaciona. Além disso, a sociedade é vista aqui como grupo de indivíduos que são iguais e livres; já a segunda, o universo reificado, é aquele em que todas as coisas, em quaisquer circunstâncias, é a medida do ser humano, e onde se encontram as entidades invariáveis, como os sistemas de estado, professores e outros, grupos diferentes que não pertencem ao universo consensual, mas pode ser obrigado a pertencer; no universo reificado, a sociedade é vista como um sistema de diferentes papéis e classes, no qual os membros são desiguais.

Essa separação é feita pelo autor para propor uma crítica à ciência, da forma como se fazia na ocasião de sua tese. Para Moscovici, a ciência constitui o universo reificado e as representações sociais o consensual. Dessa forma, o que se discute na ciência é aplicado a casos puros, isolados da realidade prática da vida cotidiana. No entanto, considerando que na própria ciência há representações sociais, Moscovici (2007) propõe uma psicologia social que seja a ciência de tais universos, que se preocupe com a problemática do universo consensual e faça a transição dela para discussão no reificado, por meio dos mecanismos representativos. Daí, surge a função das representações sociais.

A funcionalidade da teoria deriva da discussão dos mecanismos que geram as representações sociais, isto é, de sua função dentro de uma Interfaces da Educ., Paranaíba, v.10, n.30, p. 246 - 267, 2019 
sociedade pensante, e não da ação que o agente as produz, o que é algo muito discutido na perspectiva desenvolvida pela sociologia e psicologia. Sendo assim, na tentativa de engendrar a função das representações, Serge Moscovici (2007, p. 54) argumenta que "a finalidade de todas as representações é tornar familiar algo não-familiar, ou a própria nãofamiliaridade".

Uma das maneiras de elucidar esse processo é a própria tentativa de compreender o fenômeno das representações sociais, principalmente para quem não conhece a teoria, isso porque tentar compreender é em primeiro lugar engendrar representações sociais sobre a própria Teoria das Representações Sociais, e esse processo é uma maneira de tornar familiar o que não o é, de tentar conhecer o desconhecido até superá-lo.

Esse mecanismo de engendramento de representações sociais, de formulação e reformulação, funcionando como um processo necessário que ocorre por meio da tentativa de compreender um fenômeno, é uma das maneiras de caracterizar a Teoria das Representações Sociais como cognitivista, uma vez que Moscovici propõe uma tentativa de compreender como as representações são construídas no indivíduo e sugere um procedimento cognitivo processual.

Há ainda uma noção a se compreender: as formas da abordagem da Teoria das Representações Sociais, a fim de se conhecer o seu campo de imanência. Trata-se, portanto, das Abordagens Processual e Estrutural da Teoria das Representações Sociais, essas que necessitam de um estudo mais aprofundado para seu entendimento, pois há um grande arcabouço teórico a seu respeito. Contudo, é possivel fazer alguns delineamentos: inicialmente, a primeira forma de abordagem, a processual, é inaugurada com o próprio Serge Moscovici no âmago de sua tese. Para a concepção das representações sociais, utilizando-se dessa abordagem, há de se compreender a articulação de dois processos não lineares, intitulados como "ancoragem" e "objetivação". São esses os dois processos de familiarização do não familiar por meio da interação do indivíduo com o mundo.

É possível perceber a base desses processos na memória, na medida em que ancorar é trazer o objeto representacional para um intrínseco Interfaces da Educ., Paranaíba, v.10, n.30, p. 246 - 267, 2019 
universo familiar, no qual já existe uma série de outros objetos que servem como modelos, pois, a representação sobre o objeto não é gerada no vazio, mas a partir de objetos preexistentes em um local que Moscovici nomeia de núcleo figurativo (MOSCOVICI, 2007). Nele, todos os objetos familiarizados estão armazenados em forma de imagem, isso se dá pelo fato do autor trabalhar com a noção de que todo objeto é associado a uma imagem e toda imagem a um objeto (MOSCOVICI, 2012). Logo, ancorar é trazer o objeto externo para o mundo interno e compará-lo a um paradigma de uma categoria para categorizá-lo naquela que julga ser apropriada, bem como nomeá-lo. É transformar uma imagem em uma ideia.

O objeto agora internalizado e familiarizado pode ser representado. Assim, ancorar-se é trazer o objeto de fora para dentro. Objetivar é expor o objeto internalizado, ou seja, materializar a representação que se tem sobre a coisa, a fim de torná-la real, quase tangivel (MOSCOVICI, 2007). Nesse sentido, a objetivação pode ser entendida como o processo que transforma uma ideia em uma imagem, é a impressão icônica da ideia (MOSCOVICI, 2012). Então, as representações sociais compreendidas por meio desses dois processos, em síntese, é o que compõe a abordagem processual.

A segunda forma, a abordagem estrutural das representações sociais foi desenvolvida pela desterritorialização da Teoria das Representações Sociais para a reterritorizá-la no estruturalismo, como uma tentativa de objetivar o engendramento subjetivo das representações, conforme faz a abordagem processual.

A apropriação das representações sociais pelo estruturalismo deu origem a uma Teoria do Núcleo Central proposta por Jean Claude Abric (2000), cujo objetivo foi discutir a ideia de que as representações sociais são um sistema particular específico de representações, no qual sua configuração depende de dois subsistemas, sendo o primeiro o núcleo central e/ou núcleo estruturante, no qual se inserem representações originárias de uma construção sócio-histórica e, por isso, resistente a mudanças, e o segundo é o sistema periférico que comporta as representações que são construídas e desconstruídas na prática cotidiana. 
Jean Claude Abric (2003) se apropria da discussão fomentada por Moscovici de que toda representação tem uma dualidade de significado e ideia, sendo umas negociáveis e outras não. Nesse sentido, os avanços propostos por Jean Claude Abric é de que as representações negociáveis são aquelas que se inserem no sistema periférico, já as não negociáveis são aquelas encontradas no núcleo central. Dessa maneira, as primeiras podem ser compostas por representações sociais passageiras, que se transformam no decorrer do tempo e espaço, já as segundas apresentam características de resistência à mudança, compondo uma homogeneidade do grupo (ALVESMAZZOTTI, 2007). No entanto, cabe ressaltar a importância das representações do sistema periférico, pois embora possam ser passageiras, podem também não ser, evidenciando assim um potencial de transformação de todo o grupo, caso sejam transpostas do sistema periférico para o núcleo central.

Diante das noções conhecidas até aqui e aproximadamente com 55 anos de instituição, por meio da tese intitulada "A psicanálise, sua imagem e seu público" (1961), a Teoria das Representações Sociais é uma das maiores contribuições que Serge Moscovici legou à humanidade, antes de seu falecimento no ano de 2014.

\section{Metodologia}

Trata-se de uma pesquisa de campo com abordagem qualitativa, a qual, de acordo com Severino (2007), é aquela em que o objeto de estudo é abordado em seu ambiente próprio, e a coleta de dados é feita nas condições naturais em que os fenômenos ocorrem.

Participaram do estudo, enquanto sujeitos, 43 alunos do $4^{\circ}$ ano do Ensino Fundamental de uma instituição privada, na cidade de Duque de Caxias, no Rio de Janeiro, por estarem iniciando o estudo sobre os Esportes de Aventura. Desse modo, além do desenvolvimento da pesquisa, a aplicação do instrumento também serviu para contextualizar os saberes dos estudantes sobre o objeto de conhecimento proposto antes da sua tematização. Portanto, na ocasião do estudo, o grupo de participantes ainda não tinha estudado os esportes de aventura. 
A coleta de dados foi realizada por meio do teste de associação livre de palavras (SÁ, 1996; 2000), no qual os alunos escreveram as cinco primeiras palavras que lhes vieram à mente sobre o termo "esportes de aventura" e, logo após, classificaram-nas de acordo com o grau de importância, atribuindo o número um para a mais importante, até o número cinco para a menos importante.

A análise das palavras foi realizada identificando os elementos centrais e periféricos das representações, como sugerido por Sá (1996, 2000). Utilizando das fórmulas para determinação da Ordem Média de Evocação (OME), média da OME e frequência média das evocações, publicadas por Magalhães Júnior e Tomanik (2012), e Galvão e Magalhães Júnior (2016), identificamos os elementos centrais e periféricos.

De acordo com Galvão e Magalhães Júnior (2016, p.127-128),

A fórmula da Ordem Média das Evocações (OME) utiliza-se da somatória do grau de importância que os participantes atribuíram à determinada palavra ou grupo semântico, dividida pela frequência com que a palavra foi evocada, ou seja, pela soma da quantidade de vezes que o termo foi evocado.

Ainda segundo esses autores, a média das OMEs é determinada pela somatória dos OMEs de cada grupo semântico e dividido pelo número total de grupos.

Para Araújo e Magalhães Júnior (2018, p.255), as palavras evocadas devem ser organizadas em grupos semânticos, os quais juntam as "[...] palavras que apresentam o mesmo teor cognitivo e/ou são sinônimos".

Após a formação dos grupos semânticos, da determinação da OME e da frequência de cada grupo, bem como a OME média dos grupos e a frequência média, pudemos organizá-los no diagrama de Vergès, que é dividido em quatro quadrantes (ORTIZ; MAGALHÃES JÚNIOR, 2017). Segundo Araújo e Magalhães Júnior (2018), o primeiro quadrante encontrase as possiveis palavras que compõem o núcleo central das representações, por apresentarem alta frequência e baixa ordem média de evocação. Nos segundo e terceiro quadrantes encontram-se os elementos de contraste, que 
são menos acentuados na estrutura das representações sociais. No quarto quadrante encontram-se as palavras pertencentes a periferia destas representações sociais, por terrem apresentado baixa frequência e alta OME.

Todos os alunos participaram como voluntários, e seus responsáveis assinaram o termo de consentimento livre e esclarecido, sendo respeitados os critérios éticos e legais em pesquisas envolvendo seres humanos, de acordo com a Lei 466 de 2012. Cabe ressaltar que a pesquisa foi aprovada pelo Comitê de Ética em Pesquisa: CAAE de 41355114.3.0000.5283.

\section{Resultados e Discussão}

Registraram-se 215 palavras evocadas. Teixeira, Balão e Settembre (2008) sugerem que os grupos semânticos de palavras que possuem frequência igual a um devem ser descartados por não possuírem representatividade. Logo, como todos os grupos tiveram frequência maior que um, a análise foi realizada a partir do montante de 225 palavras. Em seguida, o agrupamento das palavras em grupos semânticos, formando 14 grupos. A média das ordens médias de evocação (OME) foi de 3,08, e a média de frequência (f) foi de 16,07. O Quadro 1 apresenta os quatro quadrantes com os possiveis grupos que compõem as representações sociais desse grupo antes da intervenção pedagógica de 11 aulas.

Quadro 1 - Grupos formados referentes ao termo "esportes de aventura" pelos alunos do $4^{\circ}$ ano do Ensino Fundamental

\begin{tabular}{|c|c|c|c|c|c|}
\hline \multirow{2}{*}{\multicolumn{3}{|c|}{$\begin{array}{c}\text { Elementos Centrais - 10 quadrante } \\
\text { Alta f e baixa Ordem Média de Evocações } \\
\mathrm{f} \geq 16,07 \text { e OME }<3,08\end{array}$}} & \multicolumn{3}{|c|}{ Elementos Intermediários $-2^{\circ}$ quadrante } \\
\hline & & & \multicolumn{3}{|c|}{$\begin{array}{l}\text { Alta } \mathrm{F} \text { e alta Ordem Média de Evocações } \\
\qquad \mathrm{f} \geq 16,07 \text { e } \mathrm{OME} \geq 3,08\end{array}$} \\
\hline $\begin{array}{l}\text { Grupo semântico de } \\
\text { palavras }\end{array}$ & Freq. & OME & $\begin{array}{l}\text { Grupo semântico de } \\
\text { palavras }\end{array}$ & Freq. & OME \\
\hline Esportes com bola & 32 & 2,75 & Skate/pranchas & 17 & 3,47 \\
\hline Senti & 28 & 3,04 & & & \\
\hline Saltos & 24 & 2,83 & & & \\
\hline & 23 & 3, & & & \\
\hline Expl & 19 & 2,74 & & & \\
\hline Corrida & 18 & 2,94 & & & \\
\hline \multicolumn{3}{|c|}{ Elementos Intermediários $-3^{\circ}$ quadrante } & \multicolumn{3}{|c|}{ Elementos Periféricos - $4^{\circ}$ quadrante } \\
\hline \multicolumn{3}{|c|}{$\begin{array}{c}\text { Baixa F e baixa Ordem Média de Evocações } \\
f<16,07 \text { e } \mathrm{OME}<3,08\end{array}$} & \multicolumn{3}{|c|}{$\begin{array}{l}\text { Baixa F e alta Ordem Média de Evocações } \\
\qquad f<16,07 \text { e OME } \geq 3,08\end{array}$} \\
\hline Grupo semântico de & Freq. & OME & Grupo semântico de & Freq. & $\mathrm{OME}$ \\
\hline
\end{tabular}




\begin{tabular}{|c|c|c|c|c|c|}
\hline palavras & & & palavras & & \\
\hline Esporte/Jogos & 15 & 2,80 & Agilidade/Força & 16 & 3,25 \\
Lutas & 10 & 2,60 & Esporte em água & 08 & 3,88 \\
Moto/Bicicleta & 08 & 2,88 & Tiro ao alvo & 04 & 3,25 \\
& & Tênis & 03 & 4.33 \\
\hline
\end{tabular}

Fonte: dados da pesquisa

No primeiro quadrante, notamos os seis grupos semânticos de palavras (Esporte com bola, Sentimento, Saltos Radicais, Escalada, Exploração e Corrida) que, possivelmente, são indícios dos elementos que compõem o núcleo central das representações sociais, por terem alta frequência e baixa ordem média de evocação.

Nessa perspectiva, inicialmente é importante notar a associação dos esportes de aventura aos esporte com bola, que com frequência de 32, é um elemento que possivelmente permeava o núcleo central do grupo de estudantes que fizeram parte da amostra. No entanto, embora os esportes com bola não sejam classificados como de aventura, não é raro encontrá-los em qualquer associação realizada ao termo esporte, pois de acordo com Tubino, Garrido e Tubino (2007) eles compõem a corrente esportiva intitulada "Esportes Tradicionais" que fazem referência a modalidades já consolidadas, como o futebol, handebol, basquetebol e voleibol, que no Brasil são descritos como os esportes mais praticados na cultura da educação física escolar (FARIAS; HARTMANN, 2014; TRIANI; FREITAS; NOVIKOFF, 2016), embora existam esforços de professores inovadores para mudança (SILVA; BRACHT, 2012), além de documento nacional (BRASIL, 2017).

De acordo com Moscovici (2012), as representações sociais sobre o objeto representacional se dá por meio da comunicação e, nesse caso, a mídia tem forte influência acerca das representações sociais que os estudantes compartilham sobre o esporte. Betti (2001) assinala que a mídia massifica o campo esportivo com seu vasto repertório de informações por meio da espetacularização. Logo, considerando o contexto brasileiro, há de se perceber que o futebol é o esporte mais midiático e, consequentemente, o mais familiar para os estudantes. 
Nessa perspectiva, embora já exista um consenso na comunidade científica de que os conteúdos das aulas de educação física na escola devam ser diversificados, inclusive nas diretrizes nacionais (BRASIL, 2017), estudos recentes evidenciam que os esportes com bola, ainda, são os mais praticados nas aulas de educação física escolar. De acordo com Monteiro (2016), em uma pesquisa observacional realizada em 57 escolas de São Paulo, foi identificado que o material pedagógico mais utilizado é a bola. Maldonado e seus colaboradores (2017) reforçam, ao analisar 1348 trabalhos publicados em eventos, entre os anos de 2005 e 2016, a evidência de que somente 451 tinham como características a diversificação dos temas das aulas. Além desses estudos, Paula e Batista (2016), em estudo observacional realizado nas escolas de Goiás, encontraram que os esportes com bola são conteúdo hegemônico nas aulas de educação fisica escolar e, ainda, Freire Júnior, Maldonado e Silva (2017), ao entrevistar os conteúdos ensinados por 10 professores de Educação Física, no Vale do Paraíba, identificaram que futebol, voleibol, handebol e basquetebol são os conteúdos predominantemente ensinados por meio de jogos pré-esportivos.

No que se refere ao elemento "Sentimento", esses são características fundamentais no universo dos esportes de aventura. De acordo com Le Breton (2006), a imersão nos esportes de aventura se dá pela relação de emoção sentida nas práticas corporais. Além disso, Costa (1999) acrescenta que a presença do risco mergulha o praticante no universo fictício, isto é, proporciona no sujeito a experiência da vertigem e o contato com o imaginário social. Dessa maneira, para Pereira, Armbrust e Ricardo (2008), vivenciar os sentimentos por essa prática esportiva é mergulhar na "Era do Acaso", que significa conviver com a imprevisibilidade e a possibilidade de sucesso.

Lavoura, Schwartz e Machado (2008) desenvolveram um estudo sobre os aspectos emocionais da prática de atividades de aventura, a fim de conhecer a forma pela qual os sentimentos são experimentados por um grupo que vivenciou, pela primeira vez, a prática do rapel. Na ocasião, foram encontrados sentimentos receosos, como ansiedade, insegurança e tensão, 
bem como, aqueles considerados prazerosos, como alegria, desafio e aventura.

Inácio e seus colaboradores (2015) experimentaram a inserção de práticas corporais de aventura na educação física escolar na rede municipal de Goiânia, a fim de avaliar as sensações e emoções obtidas pelos alunos durante as práticas dessas atividades. Como resultado, os pesquisadores identificaram que as práticas corporais de aventura possibilitaram desenvolveram as percepções de liberdade, confiança e autonomia dos alunos.

Nessa perspectiva, a presença de sensações, emoções e sentimentos são características próprias dos esportes de aventura, desvelando que, para o grupo investigado, são elementos do universo reificado que também estão presentes no consensual. De acordo com Moscovici (2012), os grupos podem compartilhar conhecimentos no senso comum que também estão presentes no universo reificado, da mesma forma que há possibilidade desse último estar permeado por representações sociais.

Em relação aos "Saltos Radicais", elementos que possivelmente compõem o núcleo central do grupo de alunos, esse termo citado pode ser entendido também como "manobras" que são características do esporte de aventura, presentes também nos grupos "Skate/pranchas" e "Moto/Bicicleta", emergentes nos quadrantes intermediários. Na perspectiva de Pereira, Armbrust e Ricardo (2008), embora adotem o termo "Esportes Radicais de Aventura", eles fazem referência à manobra como gesto técnico complexo. Segundo os autores, esses movimentos constituem o principal momento em que a mídia busca captar, no que tange aos esportes midiáticos, além de servirem para caracterizar a pontuação em competições esportivas. De acordo com Marchi (2017), os esportes foram alcançando a mídia na medida em que as manobras foram aparecendo.

Moscovici (2012) assinala que a comunicação de massa é uma das formas em que as representações sociais são instituídas. Nesse sentido, Betti (2001) afirma que a mídia, por meio da espetacularização, busca envolver o telespectador, mergulhando-o no imaginário social esportivo. Dessa maneira, 
da mesma forma que a mídia institui representações sociais sobre o esporte de aventura, também apresenta conhecimentos esportivos.

A Teoria das Representações Sociais (MOSCOVICI, 2012) aponta que toda imagem se associa a uma ideia e que toda ideia se associa a uma imagem. Sendo assim, a figura do herói e/ou o ídolo no esporte, permite uma familiarização com o conhecimento, como é o caso dos "saltos radicais" que podem ser associados a esportistas como Gabriel Medina e Bob Burnquist, atletas representantes dos esportes de aventura que são referenciados pela mídia de massa, por meio de comerciais de televisão, personagens de games e programas esportivos. Essas referenciais parecem ser absorvidas pelos alunos fora da escola e servem de ancoragem (MOSCOVICI, 2012) ao ser induzido a objetivar o esporte de aventura.

No que se refere a "Escalada", trata-se de um possivel elemento do núcleo central que também está presente no universo de esportes de aventura. Escalada, Montanhismo e Alpinismo são sinônimos que, na qualidade de esporte, é uma prática recente, considerando que passou pelo processo de esportivização ${ }^{4}$ a menos de 40 anos (PEREIRA, 2013). Atualmente, ao adotar a classificação proposta por Pereira (2007), têm-se as escaladas em gelo, rocha e ambientes construídos (indoor). A primeira tratase das mais altas, acima de três mil metros; a segunda, faz referência àquelas praticadas em ambientes menores, a qual possui quatro categorias, boulder, escalada livre, livre esportiva e big wall; e a terceira, devido ao controle do ambiente, o objetivo é a complexidade do movimento.

Abric (2000) assinala que o núcleo central dos grupos sociais comporta os elementos mais significativos do grupo. Com isso, ao identificar que "escalada" é um possível elemento do núcleo central, há de se perceber que mesmo antes de uma possível intervenção pedagógica os alunos já compartilham algum tipo de conhecimento sobre os esportes de aventura. Cabe ressaltar que a "escalada", após os Jogos Olímpicos do Rio em 2016, tem sido muito divulgada na mídia, por fato de ser uma modalidade que

\footnotetext{
4 Trata-se do processo que fez com que a prática conquistasse o status de esporte, a partir da sua institucionalização (TUBINO; TUBINO; GARRIDO, 2007).
} 
estará presente, pela primeira vez, na lista de modalidades olímpicas para os jogos de 2020.

A "Exploração" também se apresentou como grupo semântico que compôs o núcleo central do grupo sobre os esportes de aventura. Em termos gerais, a exploração corresponde à atividade de apreciação da natureza, fato que está presente na definição de esportes de aventura, considerado como aqueles praticados em ambientes formais e não formais vivenciados em interação com a natureza, a partir de sensações e emoções como efeito da incerteza e ao risco calculado (COSTA; MARINHO; PASSOS, 2007). Porém, uma das palavras mais comuns nesse grupo semântico foi "trilha" que faz referência à denominação atribuída à prática na natureza sem competição, sendo apenas contemplativa.

De acordo com Bernardes (2013), a trilha é intitulada com trekking, que pode se manifestar de três maneiras: o "trekking de regularidade" que se refere à caminhada esportiva, o "trekking de velocidade" ou "speed trekking", que faz referência à competição individual ou em equipes de um ponto a outro, em menor intervalo de tempo; e o "trekking", propriamente dito, é o exercício de contemplação à natureza sem fins esportivos.

No que se refere ao elemento "Corrida", identificado como possivel elemento que compõe o núcleo central do grupo, trata-se de uma representação social sobre os esportes de aventura, uma vez que, embora corridas como a de orientação estejam classificadas como de aventura, a corrida que emerge como grupo semântico faz referência ao atletismo que, de acordo com Tubino, Garrido e Tubino (2007), está no âmago dos Esportes Tradicionais.

A dimensão conceitual é uma discussão possível, considerando a associação do grupo semântico "esporte/jogos" aos esportes de aventura, emergente no quadrante intermediário. Essa possibilidade se dá pelo fato de que não é raro encontrar discussões se uma prática é jogo, esporte ou atividade (PEREIRA; ARMBRUST; RICARDO, 2008). Essa discussão está presente mesmo em âmago científico, pois para Tubino, Garrido e Tubino (2007) as manifestações são consideradas esporte, podendo ser educacional, de lazer ou de rendimento. Para Marinho, (2013) as práticas são entendidas 
como atividades de aventura, e para Pereira (2013) essas ações na escola podem ser entendidas como jogos. Embora a questão do conceito seja controversa, o documento mais atual, embora ainda em construção, no que tange à educação física na escola, faz referência a essas manifestações, entendendo-as como "práticas corporais de aventura" (BRASIL, 2017).

Dentre as associações presentes nos quadrantes, dois elementos correspondem ao universo reificado dos esportes de aventura. O primeiro "agilidade/força", com 16 de frequência, faz referência a componentes da aptidão física, indispensáveis na prática dos esportes de aventura (BERTUZZI, 2004; POBLADOR VALLEZ; TRULLEN; GOMEZ; 2008; PEREIRA, 2013). Já o segundo, "esporte em água" com frequência de 8 , trás a característica "meio", presente nos esportes de aventura, que se refere ao ambiente em que ocorrem, tendo como exemplo o mergulho e a canoagem (PEREIRA; ARMBRUST; RICARDO, 2008). É importante ressaltar que ambas as associações são indícios de possiveis representações sociais que estão presente no sistema periférico. Sob esse ponto de vista, de acordo com Abric (2000), uma intervenção pode contribuir para torna-las central, ou, caso isso não seja feito, esses elementos podem deixar de existir.

Cabe assinalar ainda que "Lutas", embora estejam presentes no quadrante dos elementos intermediários com frequência 10, trata-se de uma representação social, considerando que Tubino, Garrido e Tubino (2007) classificam essa manifestação como Esportes das Artes Marciais. Nessa mesma perspectiva, são presentes Tiro ao Alvo e Tênis, ainda que sejam associadas aos esportes de aventura, são classificados como esporte militar e tradicional respectivamente (TUBINO; GARRIDO; TUBINO, 2007).

É importante destacar que os indícios de representações sociais sobre os esportes de aventura identificados no estudo em tela correspondem a um "retrato" do momento em que a coleta de dados ocorreu. Desse modo, é cabivel refletir sobre a utilização da Teoria das Representações Sociais no estudo dos esportes de aventura para conhecer a densidade das representações sociais que são compartilhadas sobre essa temática e seus contextos emergentes. 


\section{Considerações finais}

Ao identificar e discutir as representações sociais dos alunos, no contexto da educação básica no ensino fundamental I, por meio da Teoria das Representações Sociais, foi possivel conhecer a forma de conhecimento socialmente elaborada e compartilhada, a qual desvelou que o grupo investigado atribui consensualmente sentidos aos esportes de aventura, sendo que alguns coadunam com o que é preconizado no conhecimento reificado e outros não.

Ao discutir as representações sociais compartilhadas pelo grupo, foi identificado que os alunos não sabem pontuar de maneira sustentável os diferentes conceitos de esporte de aventura, esporte radical e atividade de aventura, de outros esportes, embora tenha sido evidenciado um esforço para associar palavras ao esporte de aventura. Dessa maneira, é fundamental que uma intervenção seja realizada sobre o grupo, a fim de que vivências possam ser propiciadas e, na dimensão conceitual, discussões sobre a temática sejam realizadas, a fim de que se possa proporcionar reflexões e uma possivel transformação do núcleo central que permeia as representações sociais do grupo.

Em termos de contribuição para a prática, cabe destacar a importância de se ter bom senso quanto à aplicação pedagógica do que é preconizado na Base Nacional Comum Curricular, pois segundo o documento, os alunos somente devem ter o contato com as práticas corporais de aventura no $6^{\circ}$ ano. Essa referência parece controversa, considerando que já no $4^{\circ}$ ano, alunos podem apresentar conhecimentos sobre esse conteúdo que mereçam uma prática pedagógica de intervenção.

Esse estudo limitou-se a investigar somente um grupo de alunos do $4^{\circ}$ ano do ensino fundamental de uma instituição de ensino de dependência administrativa privada. Porém, como diretrizes para novos estudos é cabível que a investigação seja reproduzida em outros níveis de ensino, bem como verificar as representações sociais sobre a temática antes e após a aplicação do conteúdo de esportes de aventura, a fim de identificar se a prática Interfaces da Educ., Paranaíba, v.10, n.30, p. 246 - 267, 2019 
pedagógica, como efeito, proporcionou alterações nas representações sociais dos esportes de aventura.

\section{Referências}

ABRIC, J. C. A Abordagem estrutural das representações sociais. In.: MOREIRA, A. S. P.; OLIVEIRA, D. C. (Orgs.). Estudos Interdisciplinares de Representação Social. 2 ed. Goiânia: AB, 2000.

Abordagem estrutural das representações sociais:

desenvolvimentos recentes. In.: CAMPOS, P. H. F.; LOUREIRO, M. C. S. (Orgs.). Representações sociais e práticas educativas. Goiâna: UCG, 2003.

ALVES-MAZZOTTI, A. J. Representações da identidade docente: uma contribuição para a formulação de políticas. Ensaio: avaliação e politicas públicas de Educação, Rio de Janeiro, Vol. 15, n. 57, p. 579-594, 2007.

ARAÚJO, J. L. D.; MAGALHÃES JÚNIOR, C. A. O. As Representações Sociais de Graduandos no Curso de Pedagogia Sobre o "Ser Professor" de Ciências nos Anos Iniciais. Revista de Ensino, Educação e Ciências Humanas, Londrina, v. 19, n.2, p. 252-262, 2018.

BERNARDES, L. A. (Org.). Atividades e esportes de aventura para profissionais de Educação Física. São Paulo: Phorte, 2013. Enduro à pé: trekking de regularidade. In.:

(Org.). Atividades e esportes de aventura para profissionais de Educação Fisica. São Paulo: Phorte, 2013.

BERTUZZI, R. C. M. Estimativa das contribuições dos sistemas bioenergéticos e do gasto energético total na escalada esportiva indoor. Dissertação (Mestrado em Educação Física), Escola de Educação Física e Esporte, Universidade de São Paulo, São Paulo, 2004.

BETTI, M. Mídias: aliadas ou inimigas da educação física escolar? Motriz, Rio Claro, Vol. 7, n. 2, p. 125-129, 2001.

BRASIL. Ministério da Educação. Base Nacional Comum Curricular. Brasília: MEC, 2018.

COSTA, V. L. M.; MARINHO, A.; PASSOS, L. C. M. Esportes de aventura e esportes radicais: propondo conceitos. Motriz, Rio Claro, Vol. 13, n. 2 (Supl.1), p. S44-S343, 2007.

DURKHEIM, É. As regras do método sociológico. 13 ed. São Paulo: Nacional, 1987.

FARIAS, T. A.; HARTMANN, C. O esporte na escola: uma análise das modalidades esportivas mais praticadas entre os alunos do ensino fundamental II do Centro Educacional de Pesquisas Aplicada - CEPA. The FIEP Bulletin, Vol. 84, Special Edition - ARTICLE I, p. 1-5, 2014. 
FREIRE JÚNIOR, J. M.; MALDONADO, D. T.; SILVA, S. A. P. S. Estratégias para ensinar esporte nas aulas de educação física: um estudo na cidade de Aparecida/SP. Motrivivência, Florianópolis/SC, Vol. 29, n. 51, p. 28-46, 2017.

GALVÃO, C. B.; MAGALHÃES JÚNIOR, C. A. O. A relação entre as representações sociais de professores sobre educação ambiental e os projetos relacionados à Conferência Nacional Infantojuvenil pelo Meio Ambiente. Revista Eletrônica de Mestrado em Educação Ambiental, Maringá, Vol. 33, n. 2, p. 124-141, 2016.

JODELET, D. (Org.). As representações sociais. Rio de Janeiro: Ed. UERJ, 2001.

LAVOURA, T. N.; SCHWARTZ, G. M.; MACHADO, A. A. Aspectos emocionais da prática de atividades de aventura na natureza: a (re)educação dos sentidos. Revista Brasileira de Educação Física e Esporte, São Paulo, Vol. 22, n. 2, p. 119-127, 2008.

LE BRETON, D. A sociologia do corpo. Petrópolis: Vozes, 2006.

MAGALHÃES JÚNIOR, C. A. O.; TOMANIK, E. A. Representações sociais e direcionamento para a educação ambiental na Reserva Biológica das Perobas, Paraná. Investigações em Ensino de Ciências, Porto Alegre, Vol. 17, n. 1, p. 227-248, 2012.

MALDONADO et al. Perspectivas de mudança nas práticas pedagógicas da educação física escolar: uma análise dos estudos publicados nos anais de eventos paulistas. Conexões: Educação Física, Esporte e Saúde, Campinas, Vol. 15, n. 3, p. 349-367, 2017.

MARINHO, A.; SCHWARTZ, G. M. Atividades de aventura como conteúdo da educação física: reflexões sobre seu valor educativo. EFDeportes, Buenos Aires, Vol. 10, n. 88, p. 1-8, 2005.

MONTEIRO, S. R. A. F. Representações sociais, docência e práticas em educação física nas escolas rurais/campo/roça do municipio de Cunha, SP. Dissertação (Mestrado em Educação), Programa de Pós-Graduação em Educação, Universidade de Taubaté, São Paulo, 2016.

MOSCOVICI, S. A representação social sobre a psicanálise. Rio de Janeiro: Zahar Editores, 1978.

Representações sociais: investigações em psicologia social. 5 ed. Petrópolis: Editora: Vozes, 2007.

A Psicanálise, sua imagem e seu público. Petrópolis, Rio de Janeiro: Vozes, 2012.

INACIO et al. Práticas corporais de aventura [na natureza] na educação física escolar: uma experiência em escolas da rede municipal de Goiânia. Anais do Interfaces da Educ., Paranaíba, v.10, n.30, p. 246 - 267, 2019 
IXI CONBRACE - VI CONICE, 08-13 de setembro de 2015, Vitória-ES, p. 103-104, 2015.

ORTIZ, A. J.; MAGALHÃES JÚNIOR, C. A. O. Ser professor de física: representações sociais de licenciandos no primeiro ano de curso. In.: TRIANI, F.; MAGALHÃES JÚNIOR, C. A. O; NOVIKOFF, C. Representações Sociais e Educação: contextos e perspectivas. Rio de Janeiro: autografia, 2017. p.181209.

PAULA, W. M.; BAPTISTA, T. J. R. O esporte como conteúdo hegemônico das aulas de educação fisica em uma escola de Anápolis: um estudo de caso.

Kinesis, Santa Maria, Vol. 35, ed. especial, p. 51-69, 2016.

PEREIRA, D. W. Montanhismo e escalada. In: BERNARDES, L. A. (Org.).

Atividades e esportes de aventura para profissionais de Educação Física. São Paulo: Phorte, 2013.

PEREIRA, D. W.; ARMBRUST, I.; RICARDO, D. P. Esportes radicais, de aventura e ação: conceitos, classificações e características. Revista Corpoconsciência, Santo André, Vol. 12, n. 1, p. 18-34, 2008.

PEREIRA, D. W. Escalada. In.: FERRAZ, O. L.; KNINIJK, J. D. (Org.). Coleção Agôn: espírito do esporte. São Paulo: Odysseus, 2007.

POBLADOR VALLEZ, J. A.; TRULLEN, E. M. G.; GOMEZ, C. R. A. Estudio electromiográfico de la técnica del 'lanzamiento' en escalada deportiva. EFDeportes, Buenos Aires, Vol. 10, n. 75, p. 1, 2004.

SÁ, C. P. Núcleo das representações sociais. Petrópolis: Vozes, 1996.

A Representação Social da Economia Brasileira antes e depois do Plano Real. In.: MOREIRA, A. S. P.; OLIVEIRA, D. C. (Orgs.). Estudos Interdisciplinares de Representação Social. 2 ed. Goiânia: AB, 2000.

SANTOS et al. Esportes e atividades de aventura como conteúdo das aulas de Educação Física. EFDeportes, Buenos Aires, Vol. 18, n. 190, p. 1, 2014.

SILVA, M. S.; BRACHT, V. Na pista de práticas e professores inovadores na educação fisica escolar. Kinesis, Santa Maria, Vol. 30, n. 1, 2012.

TAHARA, A. K.; DARIDO, A. K. Práticas corporais de aventura em aulas de educação física na escola. Conexões: Educação Física, Esporte e Saúde, Campinas, Vol. 14, n. 2, p. 113-136, 2016.

TEIXEIRA, M. C. T. V.; BALÃO, S. M. S.; SETTEMBRE, F. M. Saliência de conteúdos de representação social sobre o envelhecimento: análise comparativa entre duas técnicas associativas. Revista de Enfermagem, Rio de Janeiro, Vol. 16, n. 4, p. 518-524, 2008. 
TRIANI, F. S.; FREITAS, W. C.; NOVIKOFF, C. Educação física escolar: as representações sociais. Conexões: Educação Física, Esporte e Saúde, Campinas, Vol. 14, n. 1, p. 130-137, 2016.

TRIANI, F. S.; MARTINS, C.; ALVES, M. P. Escalada indoor como possibilidade pedagógica para a educação física. Anais do IX Congresso Brasileiro de Atividade de Aventura e do III Congresso Internacional de Atividade de Aventura, Lavras, p. 58, 2016.

TUBINO, M. J. G.; TUBINO, F. M.; GARRIDO, F. A. C. G. Dicionário Enciclopédico Tubino do Esporte. Rio de Janeiro: Editora Senac, 2007. 